\title{
Expresiones metafóricas de la violencia en la narrativa del norte de México
}

\author{
IVÁN CAMARENa VALENZUELA ${ }^{1}$ \\ Gabriel Osuna Osuna ${ }^{2}$
}

Resumen:

El presente artículo describe y analiza la presencia de la violencia y su configuración en tres muestras representativas de la literatura contemporánea del norte de México. Durante las últimas décadas la exacerbación de la violencia ha tenido efectos profundos en las sociedades contemporáneas y sus producciones artísticas y culturales. El ámbito de la literatura no es la excepción. De ahí que analicemos las expresiones metafóricas de la violencia en las novelas Nostalgia de la sombra de Eduardo Antonio Parra y Espectáculo para avestruces de Imanol Caneyada, así como en el cuento "Eso que parece ser la vida" de Josué Barrera. Mediante estos ejemplos, trataremos de observar cómo la literatura se asigna un rostro que corresponde con los temas dominantes en el mundo contemporáneo y que han ido determinando las características del material narrativo en el siglo XXI.

Palabras clave:

Violencia, Literatura del norte de México, novela contemporánea, cuento contemporáneo.

${ }^{2}$ Universidad de Sonora. 


\section{Literatura y violencia}

La violencia es uno de los fenómenos socioculturales más alarmantes de las últimas décadas, por lo que ha sido considerada por los máximos organismos internacionales tanto un problema de salud pública como una epidemia social. ${ }^{3}$ Es así que localizar, clasificar e interpretar su expresión metafórica en algunos fragmentos narrativos de la literatura contemporánea del norte de México, nos permitirá pensar la violencia a partir de un exceso de sentido que es capaz de suspender por un momento las representaciones racionalistas habituales, de poner en duda las definiciones dominantes de los lenguajes técnicos y cuantitativos por los que apuestan las instituciones globales que la trabajan. ${ }^{4}$ La idea es hacer énfasis en la información poco obvia que la ambivalencia y la polisemia puedan ofrecer. Esto bajo el supuesto de que el exceso de sentido derivado de lo metafórico nos permite pensar lo impensado, al reconocer y reflexionar nuevas relaciones de semejanza entre términos donde reinaba la diferencia, y descubrir así algunas propiedades y significados latentes tanto en la verosimilitud de los mundos imaginarios emergentes como en la aparente objetividad de las ficciones históricas consolidadas.

Si bien es cierto que la relación entre literatura y violencia puede rastrearse en los orígenes míticos y religiosos de las diferentes tradiciones culturales del mundo, podemos decir que, para la cultura occidental, literariamente hablando, dicha relación encuentra sus fuentes más significativas en La Iliada y La Odisea de Homero, donde las grandes batallas épicas van de la mano con las más descarnadas voluntades de amor, traición y gloria. Desde entonces, las escenas violentas han tenido una presencia imborrable en la litera-

${ }^{3}$ Organización Mundial de la Salud, "Informe Mundial sobre la Violencia y la Salud", 2003.

4 Programa de las Naciones Unidas para el Desarrollo (PNUD), "Informe Regional de Desarrollo Humano 2013-2014". Oficina de las Naciones Unidas contra la Droga y el Delito (UNODC), Estudio mundial sobre el homicidio, 2013. 
tura universal. Ya sea con una intención irónica y burlesca como en Cervantes; ya sea en una puesta en escena caracterizada por la liberación criminal de los impulsos pasionales como en Shakespeare; o como el enigma y misterio que debemos resolver en los primeros relatos policiacos de Edgar Allan Poe; así como en la crudeza del realismo naturalista de Zolá, en la visceralidad descarnada de Dostoievski y el nihilismo existencialista de Camus, pasando por los padres de la novela negra como Raymond Chandler, Dashiell Hammett y Patricia Highsmith, hasta nuestros días, la representación de la violencia ha sido un motivo recurrente, una constante de la producción literaria.

\section{Lenguaje y territorio}

Ahora, si recordamos con María Antonia González Valerio que "preguntar por el lenguaje es preguntar directamente por nosotros [...] y por nuestra experiencia del mundo" (21); si recordamos que preguntar por el lenguaje es preguntar por "lo más cercano, lo más propio", y a la vez, por aquello que se nos sigue presentando "como un enigma, como lo oculto que se resiste a ser desocultado", como la "experiencia cotidiana e innegable en la que vamos siendo" (2324), encontrar la reflexión de la violencia en la literatura mexicana es hacerlo desde la propia identidad del mexicano. Lo que implica una cultura y un territorio, una idiosincrasia y una visión de mundo, un espacio social con determinadas condiciones históricas de posibilidad material, que nos invitan a pensar que la obra que el escritor construye no se organiza solo a partir de la práctica de la escritura misma, sino también, desde la interpretación personal que él hace del mundo.

Para Gadamer, dicha interpretación es una mirada, un ver que es siempre "una lectura articulada de lo que hay", pero una lectura guiada "por sus propias anticipaciones", capaz de poner y darnos también "lo que no está ahí" (131). Lo que nos explicaría ese doble vínculo que todo símbolo, que todo simbolismo, como elemento metafórico, ambiguo y polisémico, establece entre lo real y lo ima- 
ginario, entre lo objetivo y lo subjetivo, entre lo literal y lo figurativo. De ahí que en el campo nacional de las letras podamos encontrar la construcción literaria de la violencia en obras de autores revolucionarios y postrevolucionarios como Los de debajo (1916) de Mariano Azuela, La sombra del caudillo (1929) de Luis Martín Guzmán, algunos cuentos de El llano en llamas (1953) de Rulfo, o El apando (1969) de Revueltas, quienes nos mostraron en algunos paisajes emblemáticos de las letras nacionales, el dolor y la injusticia, el heroísmo y la muerte, el crimen y la venganza.

Temas y tópicos relacionados con la violencia que serían abordados desde otra perspectiva ya entrada la segunda mitad del siglo $\mathrm{XX}$, gracias al subgénero de la novela policiaca que arranca con El complot mongol (1969) de Rafael Bernal, y continúa su maduración hasta la actual hegemonía de la novela negra en el ámbito editorial, y que tiene a Paco Ignacio Taibo II y Rafael Ramírez Heredia, entre otros, como sus más visibles representantes. ${ }^{5}$

Es aquí donde entramos al territorio del norte de México. Más allá de los tradicionales debates que implican las diadas civilización-barbarie o centro-periferia, el norte de México es un espacio donde la frontera con Estados Unidos y la cultura del narco son factores geográficos y socioculturales determinantes para las comunidades. Tanto así, que resulta sencillo identificar un nutrido grupo de escritores que durante las últimas décadas han representado en su narrativa la violencia de esta región. Algunos de los más conocidos son Daniel Sada (Mexicali, 1953-2011), Rafael Saavedra (Tijuana, 1963-2013), Luis Humberto Crosthwaite (Tijuana, 1962), David Toscana (Monterrey, 1961), Heriberto Yépez (Tijuana, 1974), Yuri Herrera (Actopan, 1970) e Hilario Peña (Mazatlán, 1979). Así también, Élmer Mendoza (Culiacán, 1949) y Sergio González Rodríguez (Cd. de México, 1950-2017), quienes han trabajado la cultura del narcotráfico en Sinaloa y los feminicidios en Ciudad Juárez, respectivamente.

${ }^{5}$ Enciclopedia de la Literatura en México http:/ /www.elem.mx/estgrp/datos/50 (consultado el 24 de octubre de 2016). 
Ahora, si nos preguntamos ¿quiénes son considerados escritores del norte México?, la respuesta que nos damos incluye tanto a los nacidos como a los radicados en cualquier ciudad del norte del país. Mientras que a la pregunta sobre ¿qué se entiende por literatura del norte?, podemos respondernos que aquel conjunto de obras que transcurren, que parten, que usan como contexto o como trama, espacios e identidades, temas y tópicos regionales propios del norte de México. Sin que, por ello, estas aproximaciones sean del todo definitivas. Pues podemos encontrar en la red opiniones como las de Julián Herbert (Acapulco, 1971) para quien la literatura del norte es un fenómeno de branding editorial que ya está pasando; ${ }^{6} \mathrm{o}$ la fuerza que dicha literatura norteña ha recibido como marca en sí misma gracias a la pluma de Carlos Velázquez (Torreón, 1978), quien ha publicado algunas obras estrechamente relacionadas con el sentido identitario: La Biblia Vaquera (2008) y El karma de vivir en el norte (2013); e incluso, el sonado debate de hace algunos años entre Eduardo Antonio Parra (León, 1964) y Rafael Lemus (Cd. de México, 1977) en la revista Letras Libres, sobre las percepciones y características de la literatura del norte. ${ }^{7}$

De lo anterior, podemos afirmar que la literatura, al ser una práctica sociocultural propia de su tiempo, y sin limitarse a la falacia estilística de un realismo ingenuo, responde, ya sea asumiendo o negando, reproduciendo o recreando, los intereses y contingencias que determinan un momento histórico en un lugar específico. Lo que nos lleva a pensar desde una elemental y casi maniquea óptica de causa-efecto, que, si la producción de la narrativa contemporánea del norte de México trata de forma recurrente el fenómeno de la violencia, es porque en la actualidad estamos padeciendo una fuerte oleada de violencia que es necesario discutir desde todos los

${ }^{6}$ Herbert, Julián. "La literatura y el norte de México”. Cátedra Alfonso Reyes del Tecnológico de Monterrey, 30 abril 2014, Monterrey. Conferencia. https:// www.youtube.com/watch?v=18obX90VLwQ.

7 Parra, Eduardo Antonio. "Norte, narcotráfico y literatura", Letras Libres, no. 82, 31 oct. 2005. www.letraslibres.com/mexico/norte-narcotrafico-y-literatura. 
frentes posibles. Uno de ellos es la literatura, cuya principal misión, cabe decirlo, no recae tanto en la denuncia de un fenómeno presente en todas las épocas como el de la violencia, sino, y en especial, radica en el estilo y las nuevas formas estéticas con las que su expresión discursiva es capaz de enriquecerse para representárnoslo.

\section{Expresiones metafóricas y hermenéutica analógica}

Ahora bien, esta voluntad estética, estilística, creativa e innovadora, que la práctica literaria trata de darse a sí misma, y que los escritores persiguen de manera casi natural, es lo que se encuentra en el fondo de lo que Bourdieu (2011) reconoce como habitus literario, es decir, como la interiorización o inculcación en el individuo de la cultura literaria; de los esquemas de pensamiento, acción y percepción, que estructuran las relaciones entre las instituciones, los grupos y los agentes del campo literario, ese "mundo aparte", invertido y paradójico, en el cual se lucha por la obtención o retención de un capital simbólico; de un reconocimiento que consiste en hacerse de un nombre dentro del ámbito de las letras, a la vez que se establece una posición de "doble rechazo" hacia las determinaciones temporales del poder político y las recompensas mundanas del poder económico.

Si a estas consideraciones de la literatura como una práctica sociocultural específica, sumamos el trabajo de Paul Ricoeur, también podremos entender la literatura como "ese uso del discurso en donde varias cosas son especificadas al mismo tiempo, y en donde no se requiere que el lector escoja entre ellas", ya que el discurso literario implica "el empleo positivo y productivo de la ambigüedad" (60). De ahí la pertinencia de elegir la expresión metafórica como elemento literario clave del diseño verbal, dado que, según el mismo Ricoeur, "la desaparición de la referencia ostensible y descriptiva libera el poder de referencia a aspectos de nuestro ser en el mundo que no pueden decirse en una forma descriptiva directa, sino sólo por alusión, gracias a los valores referenciales de expresiones metafóricas y, en general, simbólicas” (49). 
Esto significa que la producción simbólica en general, y las expresiones metafóricas en particular, nos permitirán en esta ocasión pensar lo impensado, y a la vez, visualizar en el discurso literario lo que existe únicamente como potencialidad significativa, al establecer una relación creativa "entre el sentido literal y el sentido figurativo", entre el sentido explícito y el sentido implícito de la palabra (59). Y es que, para el propio Ricoeur, "la interpretación metafórica presupone una interpretación literal que se autodestruye en una contradicción significativa", siendo "este proceso de autodestrucción o transformación el que impone una especie de giro a las palabras, una extensión del significado" (63). De ahí que pueda considerársele "un error calculado, que reúne cosas que no van juntas y que, por medio de este aparente malentendido, hace que brote una nueva relación de sentido, no observada hasta este momento, entre los términos que sistemas anteriores de clasificación habían ignorado o no habían permitido" (64). ${ }^{8}$

Ahora, para asegurarnos de mantener cierta coherencia, cierto orden dentro de este mundo paradójico caracterizado por la polisemia de un discurso ambiguo, y que, gracias a sus errores calculados, a sus contradicciones significativas que se autodestruyen, produce un exceso de sentido, tomaremos en cuenta las consideraciones hermenéutico-analógicas de Mauricio Beuchot (2009), porque su modelo de interpretación busca situarse en "un punto intermedio entre la univocidad y la equivocidad, aunque da predominio a esta última”, volviéndolo así un punto de vista bastante propicio para abordar los aspectos metafóricos del discurso literario; como el propio Beuchot afirma en una clara síntesis de su propuesta:

Una hermenéutica analógica intenta abrir el campo de validez de interpretaciones cerrado por el univocismo, pero también cerrar y poner límites al campo de validez de interpretaciones

${ }^{8}$ Estos sistemas de clasificación a los que se alude son, precisamente, los discursos racionalistas dominantes del campo de poder y de las instituciones globales a los que nos hemos referido páginas atrás. 
abierto desmesuradamente por el equivocismo, de modo que pueda haber no una única interpretación válida, sino más de una, pero formando un pequeño grupo de interpretaciones válidas, según jerarquía, que puedan ser medidas y controladas con arreglo al texto y al autor. (7)

Para conseguirlo, Beuchot propone, además, la consideración de la sutileza, entendida de manera tradicional, como "un transponer el sentido superficial y tener acceso al sentido profundo, e incluso al oculto, o cómo encontrar varios sentidos cuando parecía haber sólo uno" (7-8). En otras palabras, al recurrir a la sutileza como herramienta y metodología de un modelo interpretativo, estamos recurriendo a la sutileza "tanto de entender un texto como la de explicar o exponer su sentido y la de aplicar lo que dice el texto a la situación histórica del intérprete” (30), ya que la hermenéutica tal y como Beuchot la concibe, "trata de llegar a una mediación prudencial y analógica en la que la intención del autor se salvaguarde gracias a la mayor objetividad posible, pero con la advertencia de que nuestra intencionalidad subjetiva se hace presente", para poder llegar así a la verdad del texto, que "comprende el significado o la verdad del autor y el significado o la verdad del lector", y de hecho, "vive" de la tensión dialéctica entre ambos (24). Una vez aclarados estos supuestos, no queda más que pasar al análisis de las obras literarias elegidas.

\section{Nostalgia de la sombra, o la violencia de la fragmentación interior}

Escrita por Eduardo Antonio Parra y publicada originalmente en 2002 por la editorial Joaquín Mortiz, Nostalgia de la sombra (Tusquets, 2012), es una novela que cuenta la historia de un periodista regiomontano que se transforma en asesino cuando es asaltado por tres jóvenes a mitad de una noche cargada de presagios funestos. Si bien la voz narrativa nos da una primera visión de una "ciudad infernal", de una "ciudad sin alma", pero a la vez "llena de misterio", donde cada habitante carga un demonio en las entrañas, la secuencia de las acciones cambia rápidamente esta semántica de valoración judeo- 
cristiana, por una tendencia metafórica que explora los instintos propios de la animalidad biológica y de la mutación de la identidad:

Cuando las manos del que lo registraba palparon el bolsillo donde guardaba los billetes, liberó la energía contenida. No supo cómo, ni qué lo empujó a reaccionar: de pronto se transformó en una presa que se revolvía dentro de la red. Sin esperar las órdenes del cerebro, sus puños y sus piernas se impulsaron contra los agresores. De un zarpazo apartó la navaja de su cuello y se llevó un tajo en el hombro. Ahora sí la herida le erizó el vello de la nuca, pero también fue el acicate para que la emprendiera a golpes con el que había olfateado su dinero hasta quitárselo de encima. (Parra 56)

Presa, zarpazo, olfatear, e incluso la explosión de adrenalina como energía liberada de una reacción instintiva, se convierten en la cadena de significantes que comienza a transformar la significación religiosa inicial de la voz narrativa en un conjunto de significados más propios de la visceralidad de los cuerpos, y de lo que hemos llamado violencia de la fragmentación interior. Así, lo que comenzó como una visión metafísica y profana de lo demoniaco y lo infernal, termina por mezclarse y confundirse con una mirada capaz de experimentar la trascendencia a través del dolor y el desgarramiento de la carne. Aquí la distinción entre el bien y el mal se borran en un solo episodio, y el asesinato se convierte en el umbral que le permite transitar de un mundo ordinario, productivo y familiar, a un mundo sórdido y sombrío de muerte y destrucción, donde ya nadie lo toca, donde ya ninguna moral lo ata, donde ningún miedo lo vence:

Avanzó unos pasos más y se apartaron de él como si huyeran de un perro rabioso. Entonces advirtió que aún portaba en la mano la navaja ensangrentada. La cerró y continuó su camino sin que nadie dijera nada ni intentaran detenerlo. Al llegar a la esquina escuchó una sirena y comprendió que ahora sí debía correr mientras lo sostuvieran las piernas. Cada uno de los testigos daría fe de su furor salvaje, de su sadismo, de su frialdad para matar. No importaría que sólo se hubiera defendido. (Parra 58) 
Convertido en un perro rabioso bañado en sangre, Bernardo ha perdido algo de su humanidad, ya es otro, alguien más parecido a una bestia salvaje y fría, a la que nadie puede acercársele. De ahí que no sea un ideal, un valor o una imagen, sino las piernas, simplemente las piernas, las que sostienen al protagonista en su escape de la policía. Bernardo sabe que está solo, y como cualquier animal de caza, no le queda más que profundizar en el sigilo, adentrarse en el anonimato de los márgenes, y apropiarse de la invisibilidad necesaria para el acecho, de la misma forma que el silencio se apoderó de su cabeza al darse cuenta que "el miedo se había esfumado para siempre" (59). Al parecer la memoria de lo que era se ha vaciado después del primer asesinato, y es ahora libre de toda carga moral. No hay para él, desprovisto de alma, más heridas que las del cuerpo: "Las rodillas lucían como si hubieran sido machacadas a martillazos, las manos lo mismo. La piel en los nudillos se había corrido igual que una funda y el hueso asomaba blanco en medio de la carne viva" (85).

La autodestrucción transformadora ha caído implacable sobre el trabajador, sobre el padre de familia, sobre el esposo. La piel abierta de los nudillos de Bernardo permite que la muerte se asome por sus manos, a pesar de que es solo hueso, el blanco que el lector atestigua. Sin embargo, ese blanco sólido, el blanco específico de la muerte, pudiera considerarse también un símbolo del vacío que por dentro empuja con su nívea ceguera hasta desbordarlo todo, hasta reconfigurarlo todo: "No había remordimiento, tampoco vergüenza. Aclarada la memoria de lo último que había ocurrido en su vida, revisó otra vez sus manos, sus rodillas, su cuerpo. Nada como matar a un hombre. Nada" (97).

Finalmente, cabe señalar que esta exploración del personaje principal, donde planteamos de inicio esa forma de violencia menos objetivable que la violencia física, pero que sin duda conduce a ella, y que hemos llamado provisionalmente violencia de la fragmentación interior, solo adquiere la totalidad de su sentido con las continuas metamorfosis del protagonista. Esto sucede muy avanzada la lectura, cuando se puede observar el diálogo que Bernardo entabla consigo mismo, y se sabe ya de antemano que tuvo que adoptar dis- 
tintos nombres para adecuarse a cada situación que así lo ameritaba. Si al principio estos cambios pueden considerarse como parte de un proceso de adaptación continuo, llevados al interior de la conciencia pueden considerarse una fractura en la psique del sujeto que lo dispersa sobre el fondo imaginario en el que se despliegan las posibilidades de una voz que no se reconoce a sí misma cuando habla, porque tal vez sea siempre otra al escucharse. Una voz enigmática de la que nada sabemos salvo que es la depositaria de la memoria que sobrevivirá incluso cuando el personaje haya muerto. Una voz que pudiera ser incluso, en su aspecto arquetípico, la resonancia que proviene de las regiones más sombrías del inconsciente, donde lo demoniaco se funde con lo divino, y se afirma en el sujeto la dualidad de la luz y la sombra con equivalente intensidad:

Carajo, miro mi interior y todo es lo mismo y a la vez diferente. ¿Es mío este pensamiento, o de Bernardo o del Chato o de Genaro o de Ramiro? ¿De quién es esta voz que susurra dentro del cráneo y me impone pensamientos ajenos? Una carcajada retumba en el silencio de la habitación y encuentra su timbre extraño. Vuelve a reír, intentando reconocerse, y al no conseguirlo calla. Respira con rapidez, asustado. No soy yo. No. Soy el otro que siempre susurra a mi lado. Casi nunca lo siento. Nomás en ocasiones como esta, cuando decide hacerse presente. Yo soy el que calla, incluso si la ira se inflama dentro de mí, al llegar el hambre de muerte. Callo y escucho y miro al que me habita. Yo no tengo memoria. Él sí. Por eso él seguirá de pie cuando yo haya muerto. (218)

\section{Espectáculo para avestruces, o la sacralización de la violencia criminal}

Escrita por Imanol Caneyada (1968), Espectáculo para avestruces (Arlequín, 2012) es una novela que también juega con los contrastes de la luz y la sombra sin claroscuros. Sitúa al lector en una ciudad sin nombre que pudiera ser cualquiera del norte de México. Sin embargo, el autor ha declarado en algunas ocasiones que se trata de 
Nogales, Sonora, la ciudad real detrás de la ciudad imaginaria. En la novela seguimos las acciones de RQ, un personaje que durante el día es maestro universitario, y por las noches, un asesino redentor que se encarga de poner orden en el bajo mundo. Para conseguirlo, RQ despliega una fuerte carga verbal que reviste sus fechorías con una semántica religiosa que guía, protege y condena sus pasos; prácticamente un demonio entre demonios que halla en la sacralidad de sus destrucciones los principios infernales de la creación. Al inicio de la novela, el protagonista dice lo siguiente:

Soy uno de los tantos dioses de esta ciudad desmembrada. Y como cualquier dios, una vez terminada la creación del mundo, me aburro eternidades. Por eso invento juegos macabros y perdones que justifiquen mi existencia. Camino las calles como una divinidad hastiada, y mi libre albedrío viene dictado por el capricho. Tengo mandamientos, reglas, capillas y fiestas de guardar. Los narcotraficantes, los padrotes, las putas, los asesinos, los secuestradores y los ladrones celebran todo tipo de ritos para aplacar mi ira de niño mimado. Pero como soy un dios inconstante, cada noche reinvento los dogmas, los rezos y los cánticos. Mis feligreses viven aterrados y sus fanfarronadas poseen la medida del miedo. Algún día, uno de ellos me venderá, no por treinta monedas, sino a cambio de que su vileza supere la mía. (Caneyada 17)

Las palabras de RQ sobre sí mismo no solo describen su desgracia con magnitud áurea, sino que poseen la clarividencia profética de un destino trágico que lo alcanzará. Como cualquier iluminado del abismo, RQ reúne lo divino con lo mundano, y en esa fusión de significaciones opuestas, que es ya, en sí, una violencia de orden simbólico, funda la correspondencia entre el bien y el mal por la que transita, torciendo el mundo a su favor: "Abandono el antro con un deseo loco de ser carne, instinto, cópula. ¿Qué puede haber más místico? A tres cuadras, en una esquina iluminada por los ángeles, me encuentro a una puta bella como un salmo. Sus ojos grises anuncian la presencia de la muerte. Frágil, consumida por 
la cocaína, hace la calle como quien sueña con un jardín de rosas" (20). Pequeño dios que en su bastardía no rehúye a las mieles envenenadas de lo que se presenta bajo la apariencia del amor, RQ va tejiendo relaciones con otros seres oscuros que le permitirán llegar más lejos en su misión destructora. A su vez, esto le permite al narrador ir desmontando las edificaciones más visibles de la moral en turno. Invierte los valores de la ideología dominante, al mismo tiempo que reproduce los esquemas triunfalistas con los que la sociedad del éxito, la competición y el consumo se piensa a sí misma. Y con ello, no solo desestabiliza los paradigmas discursivos haciendo estallar los lugares comunes generados por la política y los medios de comunicación, también puede decirse que libera, que promueve la emergencia de lo reprimido por el tiempo lineal de la vida productiva, para arrojar así, en la medida posible de la ficción, una luz amarga sobre el rostro inadmisible de los criminalizados.

Una imagen, una metáfora que puede representar lo anterior al interior de la trama, puede encontrarse en aquella escena donde el protagonista toma una ducha y vemos cómo la realidad cotidiana es desarticulada siguiendo el flujo del agua que lo purifica, para brotar de nuevo pero esta vez trastocada significativamente por el cuerpo deificado de RQ:

El agua se lleva la modorra y el hastío. Se lleva el rostro de mi padre, de mi madre, de Celeste. Arrasa con las tetas de la alumna y con ellas desaparecen todos los alumnos. La ciudad entera se precipita por el desagüe. La ciudad entera cabe en la cañería de ese hotel de putas y padrotes. Renace la otra ciudad, la que no tiene nombre. Con cada gota se constituye en aquelarre. Es como si brotara de mi cuerpo, y mis entrañas la alimentaran, la robusteciesen. Es como si la pariera. (46)

Si bien es cierto que hasta ahora nos hemos concentrado en fragmentos narrativos que apuntan hacia la configuración simbólica del protagonista, también es cierto que existen en la novela situaciones concretas donde la violencia homicida hace su aparición. Por ejemplo, aquella escena diurna donde RQ incita a una de sus alum- 
nas a dispararle a otro estudiante, y donde el aspecto metafórico implícito en el acto de matar lo encontramos no tanto en la retórica empleada, sino en el hecho de que el homicidio se explica por la selección arbitraria de ciertos acontecimientos del pasado de la alumna universitaria que remiten más a la problemática de la condición femenina que al presente que los personajes estaban viviendo. La alumna se deja arrastrar a la profundidad de las sombras, y cede a la tentación de la sangre alentada por las palabras mortales de un demiurgo que tiene como único acto solemne la liturgia del dolor:

El alumno no puede borrar del rostro la expresión de desprecio. Comienzo a musitar conjuros en el oído de la alumna y mantengo al chico en la mira. Le digo que concentre la furia en su mano, que registre cada centímetro de esa cara de asco en la memoria y recuerde su significado. Que piense en todas las veces que le han metido la verga y después la han dejado tirada en una cama. Que sume las ocasiones que le han dicho puta, zorra, ramera, perra. Le hablo al oído como si fuera un amante y le pido que tome la pistola lentamente. Aún la estoy abrazando cuando la Beretta cambia de mano. Un fierro enorme y pesado entre esos dedos diminutos que a duras penas alcanzan el gatillo. Soy yo quien, empujándolo por el codo, extiende el brazo de la alumna. Soy yo quien amartilla el arma. Soy yo quien guía la pistola y apunta al corazón del chico. Pero es la alumna de las tetas grandes quien tira del percutor sin cerrar los ojos. (69)

Si bien en esta escena, como ya señalamos líneas arriba, no vemos el detalle de la carne desgarrada, sí apreciamos de manera indirecta y algo distante una situación definida por el desgarro emocional. Por otro lado, es importante apuntar que Espectáculo para avestruces es una novela plagada de representaciones no figurativas de acciones violentas, como la siguiente, donde el protagonista pelea en un bar: "El cantinero se abalanzó sobre RQ con el bat en alto y descargó un golpe que RQ esquivó deslizando medio cuerpo sobre la barra. Después, recuperó la vertical y lanzó un tajo con el que 
le arrancó al cantinero medio cachete" (117). O incluso, este otro fragmento ubicado en las páginas iniciales, donde RQ consigue que uno de sus rivales pierda el miembro: "De dos saltos me sitúo a espaldas del chico hincado. Se encuentra tan drogado que su felación parece funcionar con baterías. Conrado Pesqueira adivina tarde mis intenciones. Toma al adolescente del cabello y trata de quitárselo de encima. Yo golpeo con el talón del pie derecho la nunca del mamador. Por instinto, éste cierra las mandíbulas" (19-20).

No obstante, consideramos que los fragmentos narrativos de mayor valía literaria según nuestro punto de vista, son aquellos donde el campo de la religión se funde con el campo del crimen. Dos elementos dispares que encuentran a través de la analogía sus profundas similitudes. Con esta reiteración, lo que pretendemos solamente es dar cierta circularidad temática a este apartado. De ahí que breves fragmentos como el siguiente sirvan también para ejemplificar la simbolización sacra del crimen en algunos elementos propios de ese mundo, como la droga: "La coca reverbera en mi cerebro y me regala la claridad de su evangelio" (27); "divino polvo sin corte" (73). Como las armas de fuego: "Un calibre de 9 milímetros Parabellum. Quince tiros. Quince impactos que salen tan rápido como aprietes el gatillo. Quince proyectiles como quince sugerencias, quince plegarias" (36). Como las palabras de aliento que imitan la forma de la oración, y que un asesino se repite para eliminar cualquier impedimento emocional y erigir una distancia entre él y el mundo: "No tendré. No sentiré piedad. No tendré conciencia. No sentiré culpa. No tendré dudas. Nadie me dirigirá la palabra si no es estrictamente necesario" (47). Es así como en Espectáculo para avestruces confluyen, en el ejercicio de la violencia, el carácter tanto ritual como ejecutor, de la violencia criminal representado en el arte verbal.

\section{"Eso que parece ser la vida", o la metáfora de la conciencia imprecisa}

Contraria a la experiencia de la fragmentación interna y a la sacralización del crimen, la metáfora de la conciencia imprecisa permite 
sobrevolar con éxito las posibilidades interpretativas más cercanas a la ambivalencia y la polisemia en el cuento escrito por Josué Barrera (1982), "Eso que parece ser la vida", y que apareció publicado en el libro Uno de nosotros (Tierra Adentro, 2014), donde la voz que narra nos sumerge en el suplicio padecido por un protagonista sin nombre, al que una banda de sicarios va desmembrando hasta la muerte, sin que este pierda la conciencia del todo, y más bien, oscile en un espacio despojado de tiempo que se extiende entre la memoria y el olvido a través de la voz que narra lo acontecido a la vez que reflexiona sobre su ambigua condición. Lo que abre para nosotros un horizonte interpretativo amplio, porque nos sitúa en el terreno de lo imposible a través de una intensificación de lo imaginario que, aun en su máximo esplendor, no se desprende por completo de las referencias contextuales que proporciona la mirada pretendidamente objetiva del mundo real. De ahí que el cuento comience de esta manera:

Si pudieras mirarme, sabrías que eso que parece ser tu cuerpo no es otra cosa más que pequeñas partes ligadas a un todo. Nada te pertenece. Cualquiera puede cortarte los brazos y la cabeza. Muchos aseguran que lo único que queda es la memoria, pero hay ocasiones en que ni eso. Las ideas se van, las palabras se extinguen y los recuerdos se borran. Lo que nunca falla es el olvido, por eso no entiendo por qué tengo la sensación de haber contado varias veces esta misma historia. Quizá porque son muchas historias. Cada parte de mi cuerpo tiene algo que decir. (Barrera 57)

De entrada, sabemos que el cuerpo enuncia; que es palabra y símbolo, amplio repertorio de lenguajes. Sin embargo, aquí la voz narrativa se encuentra en un estado de inmaterialidad que le impide ser percibida por algún personaje concreto, aunque se dirija en ocasiones a un tú, a una segunda persona que puede ser tanto un posible interlocutor que permanece indefinido dentro de la ficción, como un recurso de interpelación al lector mismo. Ahora, si el cuerpo habla, pero la voz que desea comunicarse carece de 
cuerpo, porque el suyo ha sido borrado de la existencia, estamos refiriéndonos a una voz despojada de su centro, y que, por decirlo de alguna manera, solo tiene su propia inmaterialidad como soporte de un desenvolvimiento que va más allá de lo físico. Como si esta voz se tratara de un significado sin significante, de un sentido que se despliega sin una narración que lo sustente. Aun así, el relato consigue una sólida coherencia estructural, y permite rastrear hasta un punto determinado lo que nuestros ojos lectores atestiguan desde el asombro, ya que la desgracia del protagonista comienza en un viaje en autobús que lo lleva junto a otros tripulantes del poblado de Los Guerra a Monterrey. Es ahí, a mitad de la noche, que un convoy de sicarios los detiene, y comienza la huida que nuestro personaje no puede concretar: "Apenas di unos pasos, que parecían más bien brincos, alguien me disparó. Me dio justo en la pierna izquierda. Caí enseguida sin poder moverme. Nadie regresó para auxiliarme, así que ahí quedé tendido, gritando, haciendo círculos con lo que fue mi cuerpo, viendo que alrededor de mí sólo había polvo" (58).

Es de notar que la voz enuncia desde un presente que es futuro respecto a la tragedia que desató la trama, intensificada porque los sicarios no dejan morir al protagonista. Al contrario, se lo llevan junto a otras personas, y es en ese trayecto cuando él comienza a experimentar en carne propia los sinsabores del descuartizamiento, aunque lo hace desde un estado de negación que le impide aceptar lo que ve, o más bien, lo que dejó de ver: "Miré mi pierna derecha pero a su lado no vi nada. La izquierda empezaba arriba de la rodilla, estaba bañada de sangre, aferrada con un trapo sucio. No pensé en nada. No concebí la idea de que faltaba algo en mi cuerpo" (59). Aquí, el protagonista ratifica la voracidad de lo real, que, como un animal hambriento, cierra sus fauces sobre nosotros. Para evitar el shock derivado de la indefensión, la voz que narra decide escapar por un momento hacia regiones más elevadas y etéreas, donde el dolor no pueda alcanzarlo: "En aquel momento cerré los ojos y no volví a saber de mí por un rato. Ya no tenía dominio del cuerpo. Me dejaba arrastrar por la velocidad de la camioneta, como si estuviera en medio de un torbellino y la fuerza del viento me elevara" (59). 
De acuerdo con Gaston Bachelard (2012), la elevación, relacionada con el eje vertical del plano cartesiano como sistema valorativo, por las propiedades de ligereza y liberación que esta implica, permite despojarnos de la gravedad y de lo bajo, del peso que fija a la materialidad de los organismos, para ascender ingrávidos en el vuelo sin alas que alienta la potencia psíquica de nuestra imaginación aérea. Potencia que al apagarse, nos regresa con la fuerza de lo súbito a la realidad a la que pertenecemos más de lo que ella nos pertenece, y es que "la realidad no es tuya; tú le perteneces a ella" (Barrera 58). De ahí que el personaje, una vez que se disipan los velos imaginarios que lo resguardaron por un instante en la improbabilidad de los mundos posibles, reciba sin mediación simbólica los arteros golpes de lo real: "No estaba seguro de lo que pasaba hasta que vi la sierra eléctrica encima de mí y después sentí que sus aspas pasaban por la otra pierna. De nuevo me desmayé, estaba seguro que iba a morir" (59-60). Ante la certeza del dolor y la muerte, el protagonista emprende una nueva fuga, pero esta vez se dirige hacia las silenciosas y remotas regiones de la inconsciencia y el olvido: “Cerré los ojos y caí de nuevo al vacío. Esta vez soñé o pensé o presentí o intuí que estaba en el camión, saliendo de mi pueblo, y que volvía a cerrar los ojos y que soñaba o pensaba a su vez en mi casa" (60).

En este punto, la conciencia de la voz que narra comienza a fragmentarse, a diluirse. Pierde noción de sí, y con esa pérdida se le escapa también la facultad para definirse y describir su propia situación. Hay, en esa voz que habla silenciosamente y mira sin ver, una fusión total entre el sueño y el pensamiento: deja de reconocer la información que sus sentidos le dictan. El caos descuartizador de la violencia ha superado la lógica ordenadora del mundo: "Añoro entender lo que sucede. El orden de las cosas te da tranquilidad" (61). Donde hay confusión no hay serenidad sino desconcierto. La voz que mira, y la mirada que habla se pierden en la ambivalencia de lo fronterizo, en la polisemia de lo extraterritorial que trastoca las demarcaciones que los límites imponen, pues se supone que donde falta un cuerpo no puede sobrevivir una conciencia. La naturaleza impertinente de lo indefinido reclama así su lugar y su herencia. Borra de un solo tajo 
las definiciones con las que la pretensión de la certeza nos alimenta. Lo real se funde con lo imaginario y cualquier símbolo que quiera dar cuenta de esa peligrosa unificación corre el riesgo de perder sus referencias comunes, sus anclajes discursivos: "Al ver mi estado, algunas personas me arrastraron hacia una de las camionetas. Apenas me subieron, arrancaron el vehículo a toda prisa. Yo iba en un estado hipnótico, pero escuchándolos. Seguía vivo, pero había muerto. Intentaba un parpadear sin resultado. No sentía el pulso pero estaba nervioso" (61).

Ya sin piernas, ya sin brazos, y delirando entre la vida y la muerte, el cuerpo del protagonista es de nuevo transportado por los sicarios que habían escapado de una balacera. Es ahí, en ese viaje rumbo a Torreón, a diez kilómetros antes de entrar a la ciudad, donde terminan de matar al protagonista, disparándole varias veces en la cabeza para después clavarle un narcocartel y dejarlo tirado en la carretera. Entonces la voz que narra vuelve a dirigirse a esa segunda persona, a ese interlocutor hipotético que puede ser tanto un personaje implícito en la ficción como el lector mismo: "Me quedé solo. ¿Me creerás si te digo que intenté escaparme? Bueno, no espero que creas nada de esta historia. Eres muy joven para conocer la realidad. La misma vida se encargará de enseñártela" (62). Aquí la voz narrativa revela ciertos datos que permiten aproximarnos a su ubicación: "Yo sólo soy alguien que te habla desde lejos en un parque. No me puedo acercar porque te asustarías. ¿Crees que la realidad es lo que miras? Pues nada es lo que es. Si alguien pudiera desprender nuestras capas nunca llegaría al centro" (62). Por supuesto que dicha localización no carece de misterio. Sabemos que la voz está lejos, oculta en un parque; puede ser vista, aunque no comprendida por su interlocutor. La incógnita aumenta cuando la voz intenta desestabilizar las apariencias con las que la realidad se comprende. Y a la vez, al aceptar que nada es lo que es, aunque sea, lanza a un mar de espejismos en las cuestiones relativas al ser, que no es ni puede ser sino a través de las apariencias que lo niegan: paradójico enigma de un sujeto que ahora se sabe descentrado.

Como el mismo protagonista afirma: "todo se vuelve impreciso cuando te falta la vida” (62), semejante imprecisión puede tener 
otras resonancias de peso, ya que además de entenderse como el hilo conductor del relato, podemos tomarla como el lugar mismo que la voz narradora habita: un lugar tan impreciso como la conciencia que solo toma forma a través de las palabras con las que esta se reviste. En este sentido, podemos afirmar también que es esta misma imprecisión la que faculta el despliegue de los recursos metafóricos más importantes. Al escapar de la pretensión de objetividad del realismo racionalista, dirigimos el discurso literario hacia los horizontes más amplios que la psique pueda concebir: los horizontes imaginarios erigidos sobre el magma arquetípico de la potencialidad pura. Sin embargo, para el protagonista, para la voz que narra, todo esto que pretendemos elevar al grado de una reflexión creativa no es otra cosa que un "limbo", un espacio vacío, una nada al interior de la nada que le impide encarnar en otro cuerpo, en otro nombre, en otra voz.

Ahora, nos equivocamos al creer que el cuento llega a su fin cuando nos acercamos en retrospectiva al momento en el que asesinan al protagonista, pues los tormentos del personaje sin nombre no acaban con su muerte a manos de los sicarios: el trozo que le queda de cuerpo es transportado a la morgue donde le practican una autopsia que él mismo narra con detalle desde su no ser. Aquí es donde los médicos forenses separan su cabeza del resto del tórax, y nos damos cuenta que la voz que habla se encuentra ligada a esta parte superior del cuerpo, incluso cuando ya antes había indicado la posibilidad de que piernas y brazos actuaran y pensaran por sí mismos. Pero no, seguimos a la cabeza en un nuevo viaje hacia un laboratorio donde es acompañada por otras cabezas con las que charla. Al estar en manos de los laboratoristas podemos enterarnos que las cabezas son revisadas con la intención de extirparles los órganos funcionales y luego ser desechadas. La cabeza de la vOz protagonista no tuvo un destino diferente, y vemos que le desprenden las retinas, la mejilla derecha y los labios, con lo que se funda un paralelismo inédito entre doctores y sicarios, pues ambos grupos sociales practican a su manera distintas formas de la mutilación y el desmembramiento. Otro dato importante en este momento de la trama, es que la ubicación de la conciencia parlante vuelve a cam- 
biar, pues ya no es la cabeza en general, sino los labios en particular, el sitio concreto donde ahora brota la voz imprecisa. Una voz que ha vuelto a perder otro grado en la conciencia de sí: "Una de las personas me sacó, los sacó o nos sacó y los colocó en un recipiente con lo que parecían ser otros labios... La bandeja en donde los-nos juntaron la-nos metieron en una máquina en donde los-nos trituraron para hacer un tejido especial para sabrá Dios quién o para qué motivo. Fue ahí cuando me desprendí por completo" (64).

Sin duda, la trituración es el nivel más profundo de la mutilación, ya que en ese acto no quedan rastros de lo que alguna vez fue, y lo uno se mezcla con lo otro hasta volverse indiferenciable, de ahí que en esa escena se haya dado el desprendimiento final entre la conciencia parlante y el cuerpo mudo. Los recursos gramaticales que el narrador utiliza para lograr este efecto ("me sacó, los sacó o nos sacó", "los-nos", "la-nos") refuerzan la tendencia hacia la imprecisión previa al desprendimiento total. Después, según la misma voz que nos ha hablado a lo largo de la narración, solo le quedó algo parecido a una "memoria" que, sin saber por qué, un par de jóvenes destruyen como si de un objeto material se tratara; en concreto, como si fuera "una bomba a punto de estallar" (64). Vemos un proceso de deconstrucción que pareciera no terminar en otra cosa que en una entidad abstracta que no sabe de sí, que no puede ubicarse ni expresarse como quien desea hacerse escuchar. Y sin embargo sabemos de ella, de ello, en su monólogo sin palabras por la fuerza tan creadora como destructora de la imaginación: "Mi aliento enmudeció junto con la memoria, se desgarró, se desfragmentó en pequeñas partes que por sí solas no sirven de nada. Por ese motivo ya no sé quién soy y no estoy seguro de si soy algo aún, pero aquí sigo inerte, inexpresivo, inmóvil, frágil, sin nada que dar" (65).

\section{A manera de conclusión}

En primer lugar, podemos afirmar que las respuestas que encontramos a partir de nuestras interrogantes sobre el vínculo entre el fenómeno sociocultural de la violencia y las expresiones metafóri- 
cas del discurso literario que lo abordan, de entrada, al ser diseños verbales, y al estar enmarcadas en el horizonte del lenguaje, nos hablaron de nosotros, pero desde la otredad, desde lo reprimido y marginado; de ahí que, si arrojaron alguna luz sobre el conocimiento de la realidad social, esa luz provino de los rincones más oscuros y torcidos.

En segundo lugar, podemos constatar que la construcción y uso de conceptos impuros, híbridos, en los que podemos encontrar la resonancia de otras disciplinas del saber, nos llevó a situarnos en una posición fronteriza entre la visión humanista de la práctica literaria y la perspectiva crítica de las ciencias sociales, a través de la cual, pudimos explorar tanto los efectos performativos de la voluntad de poder en el caso de los asesinos solitarios, como los efectos de la destrucción y el sufrimiento individual en el caso de la víctima desmembrada.

En tercer lugar, podemos señalar que la puesta en duda de los discursos dominantes de la economía y la política basados en el racionalismo cientificista de los lenguajes técnicos, cuyos resultados no van más allá de las mediciones cuantitativas del positivismo, y del tono alarmista con el que los medios de comunicación reproducen dichos discursos, se vuelve un recurso intelectual adecuado, cuando lo que se quiere es permanecer lo más cerca posible de un análisis creativo de la literatura, y que en este caso, nos permitió esbozar unas cuantas formas alternativas de adjetivar el fenómeno de la violencia en el norte de México.

En cuarto lugar, podemos afirmar que este desplazamiento, esta suspensión de los discursos más cristalizados, más solidificados y reproducidos socialmente hablando (como los discursos de la economía, la política, la ciencia y los medios de comunicación), nos permitió abrir para el arte literario del norte de México, un espacio de posibilidad reflexiva caracterizado por la asimilación prudente y sutil del equivocismo relativista propio de su discurso metafórico y polisémico.

Finalmente, más allá de las visiones antagónicas que afirman o niegan la emergencia y consolidación de la literatura norteña en estas primeras décadas del siglo XXI, nos queda asumir y defender una 
posición que conecta con dicho objeto de estudios a partir de una doble vía estrechamente ligada: la vía del discurso y la vía del espacio. Entre ambas, el escritor del norte se reconoce y se desconoce, establece alianzas y enemistades, juega y compite, gana y pierde el pan de cada día, produce y reproduce el sentido, habita el mundo, crea y transforma la realidad.

\section{Bibliografía}

Bachelard, Gastón. El aire y los sueños. Ensayo sobre la imaginación del movimiento. FCE, 2012.

Barrera, Josué. Uno de nosotros. Tierra Adentro, 2014.

Beuchot, Mauricio. Tratado de hermenéutica analógica. Hacia un nuevo modelo de interpretación. Unam/Ítaca, 2009.

Bourdieu, Pierre. Las reglas del arte. Génesis y estructura del campo literario. Anagrama, 2011.

Caneyada, Imanol. Espectáculo para avestruces. Arlequín, 2012.

Gadamer, Hans-Georg. Verdad y método 1. Sígueme, 2012.

González, María Antonia. Un tratado de ficción. Ontología de la mímesis. Herder, 2010.

Oficina de las Naciones Unidas contra la Droga y el Delito (UNODC). Estudio mundial sobre el homicidio, 2013. www.unodc.org/ documents/gsh/pdfs/GLOBAL_HOMICIDE_Report_ExSum_ spanish.pdf.

Organización Mundial de la Salud. Informe Mundial sobre la Violencia y la Salud, 2003. www1.paho.org/spanish/am/pub/violencia_2003.htm.

Programa de las Naciones Unidas para el Desarrollo (PNUD). Informe Regional de Desarrollo Humano 2013-2014. Seguridad Ciudadana con rostro bumano: diagnóstico y propuestas para América Latina, 2013. www.latinamerica.undp.org/content/rblac/es/home/library/ human_development/informe-regionalde-desarrollo-humano2013-2014-.html.

Parra, Eduardo Antonio. Nostalgia de la sombra. Tusquets, 2004. 
Ricoeur, Paul. Teoría de la interpretación. Discurso y excedente de sentido. Siglo XXI, 2003.

Zizek, Slavoj. Sobre la violencia. Seis reflexiones marginales. Paidós, 2009. 